\title{
Intraoperative electromagnetic navigational bronchoscopic localization of small, deep, or subsolid pulmonary nodules
}

\author{
Abbas Abbas, MD, ${ }^{\mathrm{a}}$ Sagar Kadakia, MD, ${ }^{\mathrm{b}}$ Vishnu Ambur, MD, ${ }^{\mathrm{b}}$ Kimberly Muro, PA, ${ }^{\mathrm{a}}$ and \\ Larry Kaiser, MD
}

\begin{abstract}
Background: Localizing small or deep pulmonary nodules or subsolid groundglass opacities often is difficult during video-assisted thoracoscopic surgery (VATS) or robotic-assisted thoracoscopic surgery (RATS). This can result in larger resections or conversion to thoracotomy. The goal of this study is to evaluate the role of electromagnetic navigational bronchoscopic localization (ENBL) as a safe and accurate intraoperative method to localize small, deep, or subsolid nodules.
\end{abstract}

Methods: This is a single-institution, single-surgeon retrospective study of all patients (51) who underwent combined ENBL and resection of 54 nodules between May 2013 and August 2015. Localization was performed by intraoperative ENBL-guided transbronchial injection of a liquid marker. The liquid marker used was methylene blue, either alone or in addition to indocyanine green and Isovue. A fiduciary also was added in 2 cases. Immediately after localization, the patients underwent VATS for evaluation before proceeding with RATS for anatomical sublobar resection.

Results: The mean preoperative largest nodule diameter on computed tomography scan was $13.3 \mathrm{~mm}$ (range, $4-44 \mathrm{~mm}$ ). The mean distance from the surface of the lung to the middle of the nodule was $22 \mathrm{~mm}$ (range, $4-38 \mathrm{~mm}$ ). Thirty-one nodules were solid (57.4\%), whereas 23 were ground-glass opacities $(42.6 \%)$. ENBL successfully localized the nodules for initial sublobar resection in 53 of 54 nodules $(98.1 \%)$. Minimally invasive thoracoscopic surgery was performed successfully in 49 of 51 patients $(96.1 \%)$, by RATS in $47(92.2 \%)$, and VATS in $2(3.9 \%)$. Two patients required conversion to thoracotomy secondary to extensive adhesions. Of the 54 nodules, final diagnosis was adenocarcinoma in $32(59.2 \%)$, metastatic disease in $7(13 \%)$, squamous cell carcinoma in $2(3.7 \%)$, neuroendocrine tumor in $2(3.7 \%)$, and benign in 11 $(20.3 \%)$. There were no operative mortalities. Morbidities included acute renal insufficiency in 2 patients and prolonged air leak requiring a Heimlich valve in 3 patients. Mean length of stay was 3.9 days.

Conclusions: ENBL is a safe and accurate intraoperative modality for targeted sublobar resection of pulmonary nodules that are deemed difficult to localize. (J Thorac Cardiovasc Surg 2017;153:1581-90)

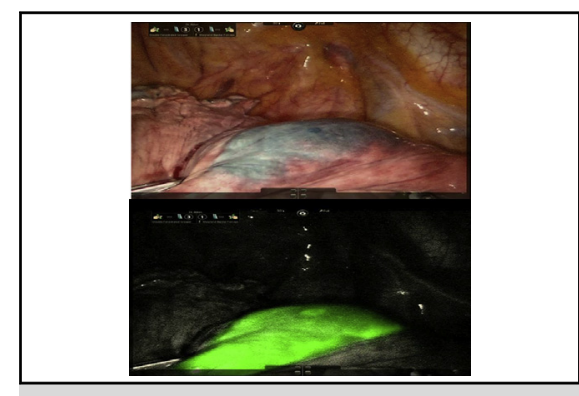

Electromagnetic navigational localization injection.

Central Message

Electromagnetic navigational bronchoscopic injection of markers is a safe and accurate technique for localizing small, deep, or subsolid nodules during robotic and conventional thoracoscopic surgery.

Perspective

Localizing small, deep, or subsolid nodules may be difficult during robotic or conventional thoracoscopic surgery. This can result in larger resections, conversion to thoracotomy, or failure to find the target lesion. Our experience shows that intraoperative electromagnetic navigational bronchoscopic injection of markers is both safe and accurate for targeted sublobar resection of these nodules.

See Editorial Commentary page 1591.

\footnotetext{
From the Departments of a Thoracic Medicine and Surgery and ${ }^{\mathrm{b}}$ Surgery, Temple University Hospital, Lewis Katz School of Medicine, Philadelphia, Pa. Read at the 96th Annual Meeting of The American Association for Thoracic Surgery, Baltimore, Maryland, May 14-18, 2016.

Received for publication Aug 12, 2016; revisions received Nov 11, 2016; accepted for publication Dec 3, 2016; available ahead of print March 14, 2017.

Address for reprints: Abbas E. Abbas, MD, Department of Thoracic Medicine and Surgery, Temple University Hospital, Lewis Katz School of Medicine, $3401 \mathrm{~N}$ Broad St, Suite C-100, Philadelphia, PA 19035 (E-mail: abbas.abbas@temple. edu).

$0022-5223 / \$ 36.00$

Copyright (C) 2017 by The American Association for Thoracic Surgery

http://dx.doi.org/10.1016/j.jtcvs.2016.12.044
}

Lung cancer is the most common cancer worldwide. In the United States, although it is not the most common, it remains the leading cause of cancer-related death, accounting

Scanning this QR code will take you to a supplemental video for the article. To view the AATS 2016 Webcast, see the URL next to the video thumbnail. 


\section{Abbreviations and Acronyms}

$\mathrm{CT}=$ computed tomography

$\mathrm{ENBL}=$ electromagnetic navigational

bronchoscopic localization

GGOs $=$ ground-glass opacities

ICG = indocyanine green

IPN = indeterminate pulmonary nodule

$\mathrm{MB}=$ methylene blue dye

NIR $=$ near infrared

RATS $=$ robotic-assisted thoracoscopic surgery

VATS $=$ video-assisted thoracoscopic surgery

for $28 \%$ of annual cancer mortality. There is therefore a justified concern when indeterminate nodules are discovered on imaging studies. In addition, there has been an exponential increase in the number of chest imaging studies, especially computed tomography (CT) scans. This is attributable to several indications, including lung cancer screening for at-risk individuals, evaluation of cardiopulmonary disease, and to rule out pulmonary metastatic disease. As the result of these factors, thousands of individuals will be found to have indeterminate pulmonary nodules (IPNs).

It is interesting that the National Lung Cancer Screening Trial, which demonstrated that participants who received low-dose helical CT scans had a relative reduction in mortality from lung cancer of $20 \%$ with low-dose CT screening also demonstrated that $96.4 \%$ of the positive screening results were false-positive results. ${ }^{1}$ It is therefore important to set criteria for those nodules with high probability of malignancy. This often depends on the patient's risk factors but, in general, when the screened nodule persists or enlarges on serial scans or has a solid component $\geq 5 \mathrm{~mm}$, the risk of malignancy is high. ${ }^{2}$

The nonsurgical options for biopsy of an IPN include image-guided percutaneous or endoscopic modalities. Unfortunately, most of these nodules are difficult to biopsy with these techniques because of their small size, deep location, or their subsolid nature in the case of groundglass opacities (GGO). ${ }^{3,4}$ In fact, these same characteristics also make them frequently difficult to visualize and palpate during minimally invasive or even open surgical procedures. An example of such a nodule can be seen in Figure 1. This nodule is small $(8 \mathrm{~mm})$ and located in an area difficult to biopsy or palpate. It had no visible pleural reaction at the time of surgery.

Because the standard for surgical lung biopsy has shifted from thoracotomy to thoracoscopy as the result of its many proven benefits, so too has the ability of the surgeon to rely on bimanual palpation for localization of an IPN. It has therefore been necessary to develop techniques that can assist the surgeon in accurately localizing such a nodule

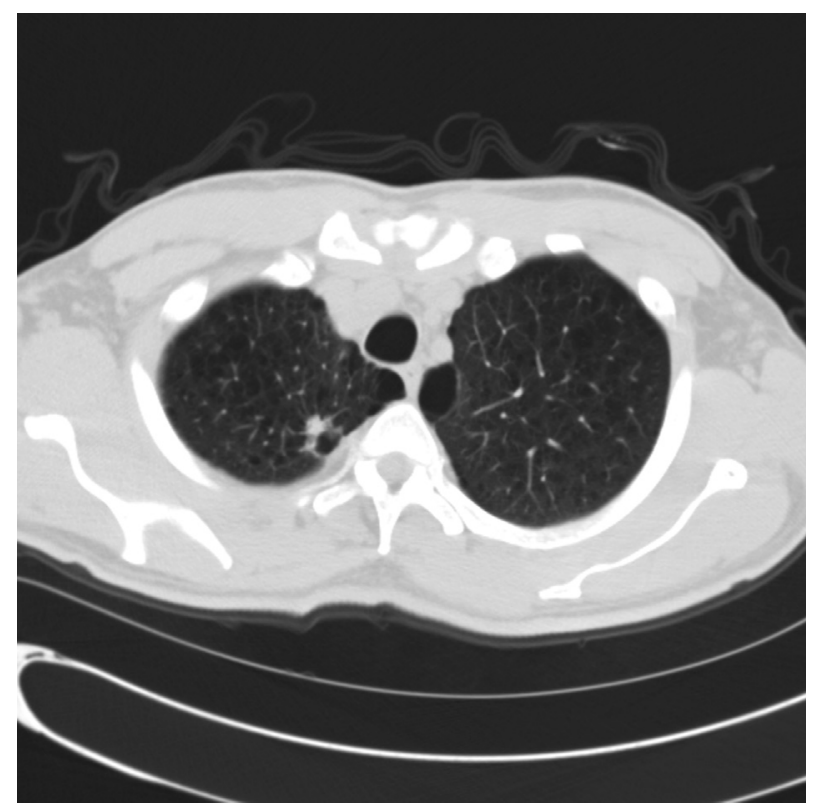

FIGURE 1. Example of a small 8-mm nodule that is difficult to percutaneously biopsy or thoracoscopically palpate. At the time of surgery, there also was a lack of pleural reaction other than the injected dye. Frozen section examination of the wedge resected nodule confirmed it to be a granuloma.

to avoid the possibility of missing the lesion, converting to thoracotomy, or having to unnecessarily perform a larger resection.

Numerous techniques for localization of pulmonary nodules before resection have been described, mostly in the form of preoperative, CT-guided placement of hooks, coils, radiotracer, and dyes. ${ }^{5-20}$ Endoscopic techniques also have been described, including both fluoroscopyguided $^{21}$ and, more recently, electromagnetic navigational bronchoscopic localization (ENBL) ${ }^{22-25}$ for the placement of dye markers or fiducials. Each method has advantages and disadvantages. They all share the potential for causing pneumothorax, contusion, bleeding, and in the case of wires, possible dislodgement. In addition, the fact that the team doing the localization usually is not the same as that performing the surgery creates a potential for miscommunication regarding the location and proximity to the nodule. Intraoperative options, in contrast, include using single digital palpation of the lung or ultrasound probe localization. ${ }^{26,27}$

ENBL has been available for more than a decade. It was designed to localize and guide endoscopic tools through the airway to a target lesion. The system consists of an electromagnetic tracking system that detects a position sensor incorporated into a flexible catheter which can be advanced through a bronchoscope. An electromagnetic field is generated by a localization system (a processor, amplifier, and a location board). When the sensor is placed within the 
electromagnetic field, its position and orientation can be identified and this information is superimposed on previously acquired high-resolution CT data, creating 3 -dimensional virtual bronchoscopy images. ${ }^{28}$

Although initially developed for biopsies, it also has been used successfully in localization techniques and the placement of fiducials for radiation therapy. It has become widely available and currently is used by both thoracic surgeons and pulmonologists.

The purpose of our study was to determine whether intraoperative ENBL of IPNs by the same thoracic surgeon performing the resection can provide a safe and effective modality for sublobar resection of an IPN via thoracoscopic techniques.

\section{MATERIAL AND METHODS}

After approval from the institutional review board, the thoracic surgery database at our institution was reviewed retrospectively. All patients who underwent a combined ENBL of a lung nodule followed by resection from May 2013 to August 2015 were included. The lung resections were all performed by a single surgeon. A multidisciplinary team that includes thoracic surgeons, chest radiologists, and interventional pulmonologists evaluates all our patients who undergo surgery for suspicious nodules. Careful study of the CT scans also was performed routinely to identify the segmental location of these nodules. Any nodule that was clearly confined within segmental borders (eg, lower lobe superior segment) was not selected for ENBL and simply underwent resection of that segment. The same team also determined the need for preoperative biopsy of these nodules. In our institution, diagnosis of peripheral nodules is attempted mostly by CT-guided needle biopsy whereas that of more central ones by ENBL. Thirty-eight patients underwent attempted biopsy with inconclusive results, whereas 13 patients had nodules deemed too small or inaccessible. The patients selected to undergo this procedure were those who had nodules that were deemed as potentially difficult to localize as the result of small size, deep location, or subsolid nature.
Data were collected on both patient and nodule specific characteristics. Patient demographics and comorbidities were identified. Various characteristics of the nodules, including number, location, size, and depth from the pleural surface of the lung, also were collected. In addition, data were collected on operative characteristics, final pathology, and clinical outcome. The histopathology of the resected nodules was classified according to the World Health Organization criteria of 2015.

\section{Data Analysis and Statistical Considerations}

The baseline patient and nodule specific characteristics, operative characteristics, final pathology, and clinical outcome were reported with the use of descriptive summary statistics such as mean, standard deviation, and range for a continuous variable (eg, age and size of nodule) and frequency and percentage for a categorical variable (eg, sex and comorbidities).

\section{ENBL Planning and Procedure}

During the preoperative planning phase, a CT scan was obtained with 1-mm slices. Mapping was performed with the superDimension Electromagnetic Navigation Bronchoscopy system (iLogic, Minneapolis, Minn). The first step involved loading the CT images onto the virtual bronchoscopy planning software. The software then reconstructed axial, coronal, sagittal, and virtual bronchoscopic views. After we identified various anatomical registration points (carina and each lobar orifice), the target lesion was outlined and a pathway from the trachea to the target was mapped.

The navigation procedure was performed after the patient was intubated with a single lumen endotracheal tube. After a routine surveillance bronchoscopy, a locatable guide, which allows for tracking of position and orientation inside an extended working channel, was inserted into the bronchoscope. Registration was then performed, which correlated the anatomy seen on the CT scan with the images obtained during the bronchoscopy. The virtual planned pathway was then followed down to the target nodule. Fluoroscopy was used to determine the position of the locatable guide (Figures 2 and 3), which subsequently was removed and a bronchoscopy needle inserted into the extended working channel. After confirmation of the location of the needle with fluoroscopy, $1 \mathrm{~mL}$ of a marker solution was injected into the nodule. When the nodule was more

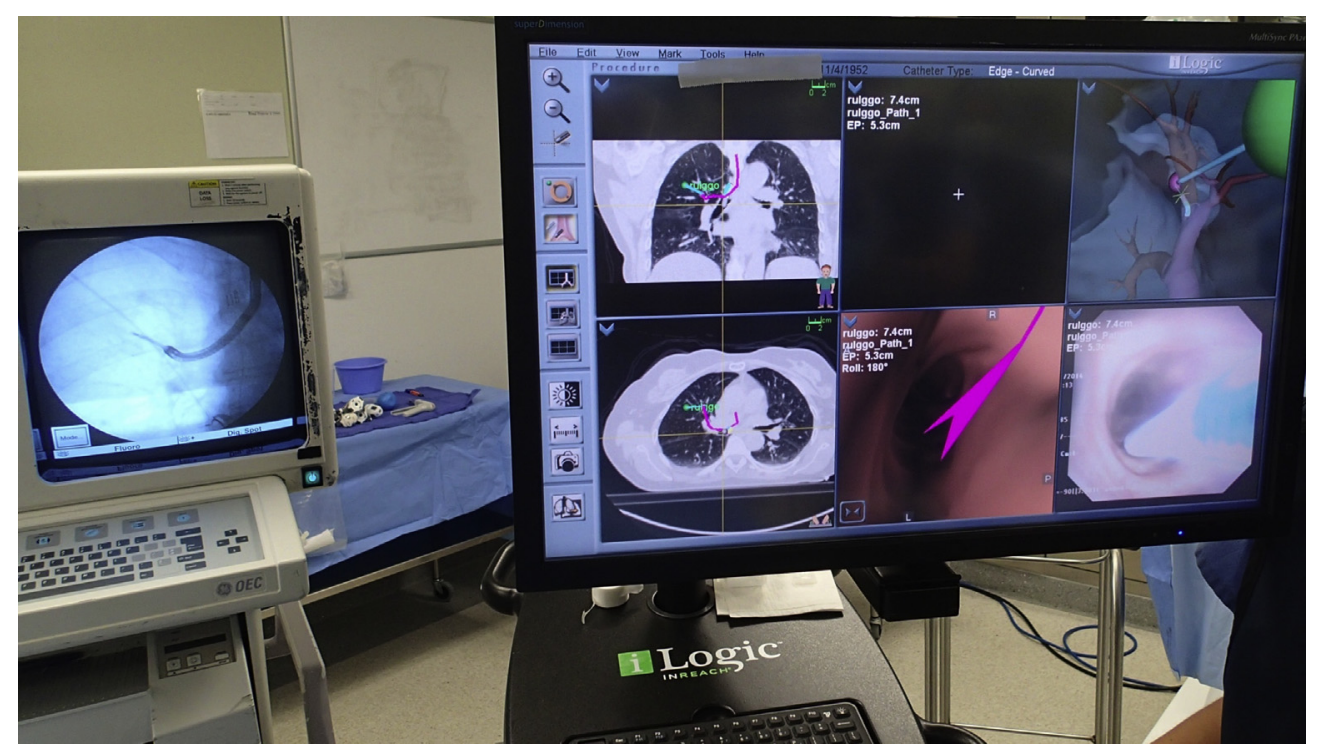

FIGURE 2. The monitor on the left depicts fluoroscopic confirmation of the tip of the catheter in position to inject the dye. The monitor on the right displays the CT scan and planned pathway to the nodule. 


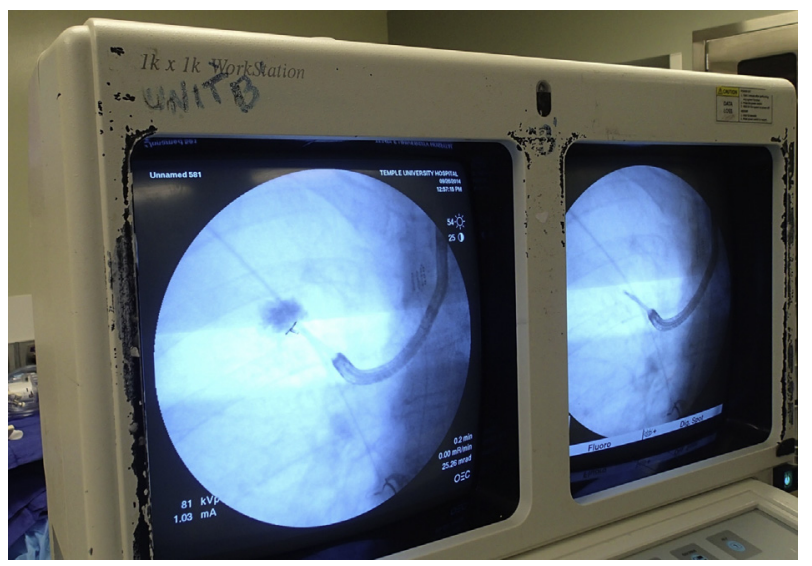

FIGURE 3. Fluoroscopic visualization of radiopaque Isovue dye injection.

than $20 \mathrm{~mm}$ deep, a second injection of $0.5 \mathrm{~mL}$ was administered close to the overlying pleura.

Initially, we used methylene blue dye (MB) with fiducials for our first 2 patients. We found little benefit from using the fiducials and therefore switched to MB only for the next 19 patients in the study. In our experience, however, the MB dye tended to diffuse into the surrounding lung parenchyma, as has been reported by others. ${ }^{23,29}$ In addition, we felt there was a benefit to being able to monitor the injection under fluoroscopy, which already is available for the ENBL procedure. We therefore switched to a mixture of Isovue (Bracco Diagnostics, Konstanz, Germany), which enables fluoroscopic detection, $\mathrm{MB}$, which is readily visualized on the pleura, and indocyanine green (ICG), which is detectable as fluorescent green, while using the near infrared (NIR) laser-equipped robotic endoscope (Firefly Mode; Intuitive Surgical Inc, Sunnyvale, Calif). We used the same dose described by Yamashita and colleagues, ${ }^{30}$ ie, 1 to $2 \mathrm{~mL}$ injected bronchoscopically into or adjacent to the tumors. In our experience the MB allows initial visualization of the general location of the nodule but tends to rapidly diffuse to a larger area whereas ICG tends to remain more localized at the site of injection. This quality of ICG also has been corroborated by other investigators. ${ }^{24}$

\section{Surgical Procedure}

Immediately after ENBL, an ipsilateral bronchial blocker was inserted and the patient turned in the lateral decubitus position. After placing the first robotic 8-mm port, usually in the eighth or seventh intercostals space, we began with thoracoscopy for initial evaluation of the pleural space and for accurate placement of the remaining robotic ports. Unless there was a clear indication to convert to thoracotomy because of adhesions or if the

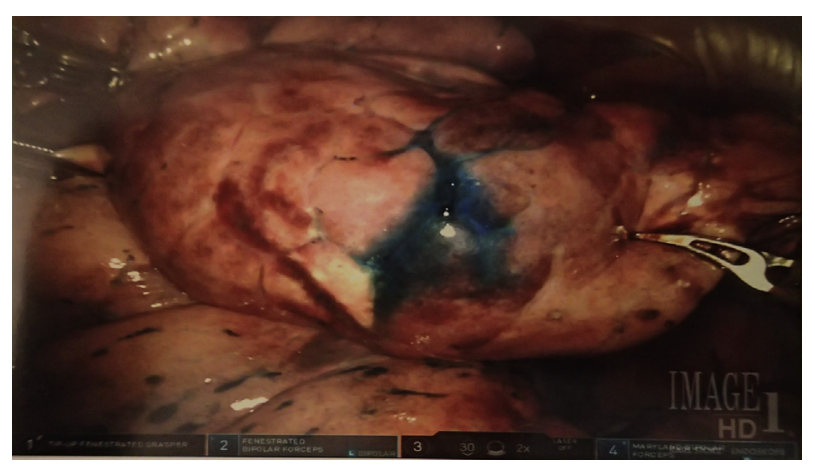

FIGURE 4. Methylene blue identified at the pleural surface.

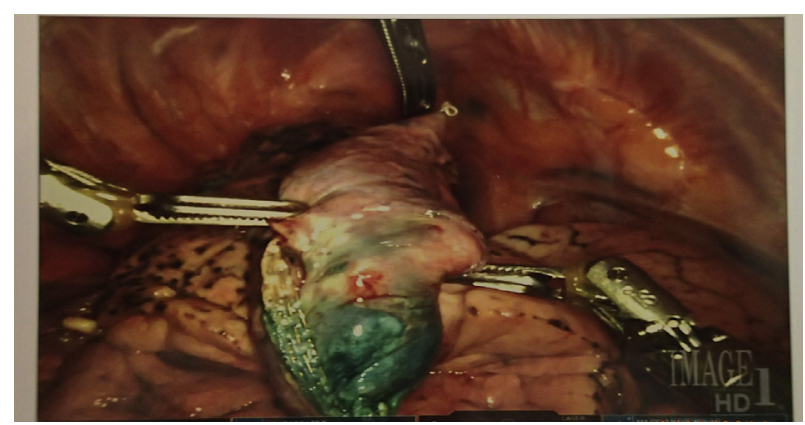

FIGURE 5. Wedge resection guided by the location of the dye.

nodule was superficial and readily accessible to simple video-assisted thoracoscopic surgery (VATS) resection, we proceeded with placement of 3 other $8-\mathrm{mm}$ ports in the same intercostal space in addition to a $15-\mathrm{mm}$ assistant port in the 10th subcostal space.

After placement of all the planned ports, digital palpation of the lesion routinely was attempted for all potentially palpable nodules. No additional utility incisions were made for lesions too far from the port sites. After docking the robotic arms, we proceeded with robotic-assisted sublobar resection (wedge resection or segmentectomy) after identification of the dye-marking (Figures 4-7, Video 1). Intraoperative pathologic frozensection analysis was obtained for all nodules. Further anatomical resection, including segmentectomy and lobectomy, was performed if a nodule was confirmed to be primary lung cancer, if the margin was too small, or if the nodule was not identified in the resected specimen. All of the patients with primary lung cancer also underwent systematic mediastinal lymph node dissection. On completion, an intercostal nerve block was performed from the sixth to the 10th intercostal nerves and a chest tube was placed through the anterior port site followed by re-expansion of the lung and checking for air leaks.

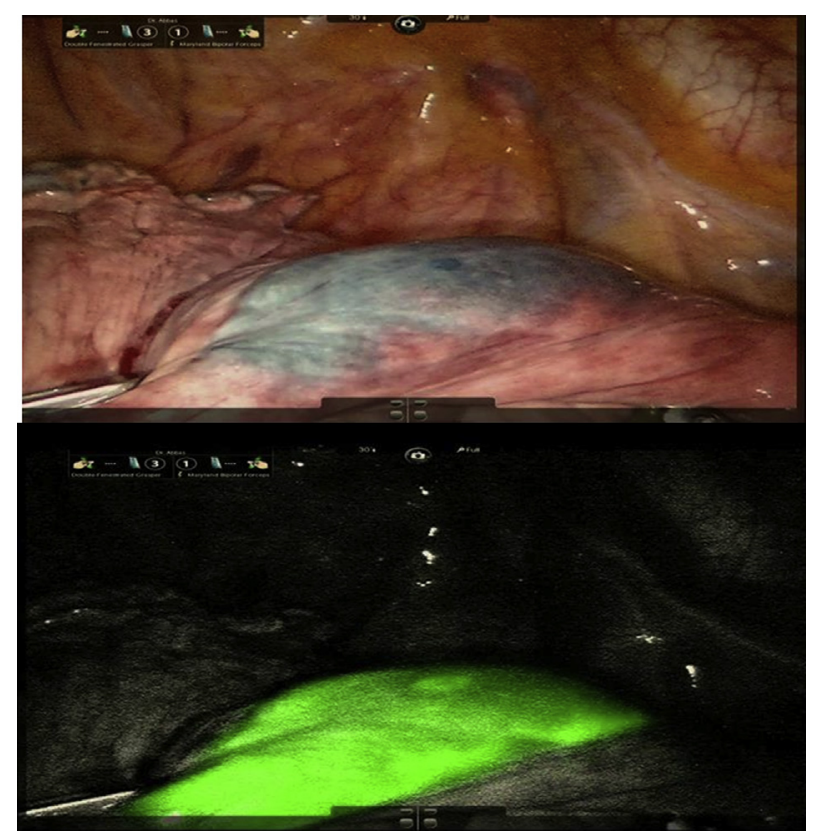

FIGURE 6. NIR fluorescence of ICG. Upper image shows blue methylene blue whereas the lower image shows the stark fluorescent effect when subjected to NIR light. 


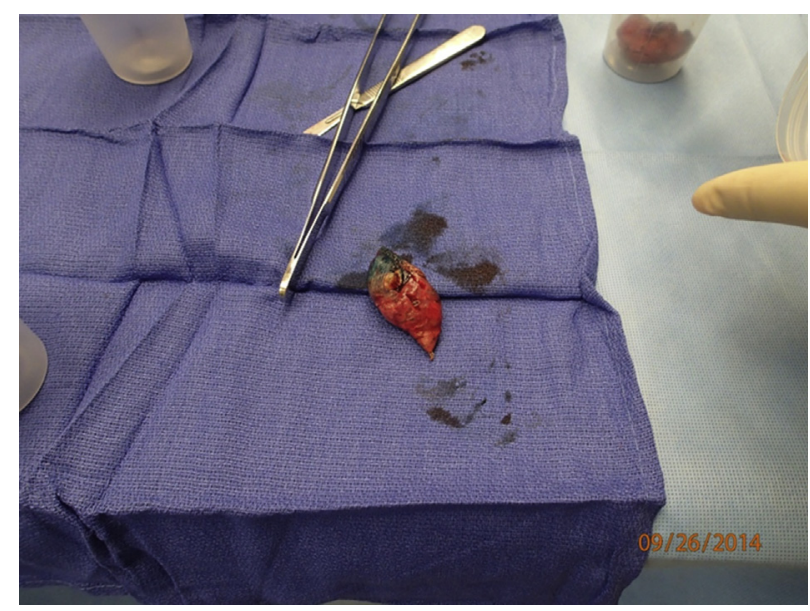

FIGURE 7. Final wedge specimen.

\section{RESULTS}

\section{Patient Characteristics}

Between May 2013 and August 2015, 51 patients (26 male and 25 female) underwent ENBL of 1 or more IPNs followed by immediate resection (Table 1). The mean age was 62.6 years (41-86 years). A history of smoking or chronic obstructive pulmonary disease was present in most patients $(88.2 \%$ and $60.8 \%$, respectively). Seven patients $(13.7 \%)$ had previous ipsilateral thoracotomies.

\section{Nodule Characteristics}

Preoperative data. There were 54 nodules in total with 3 patients having 2 nodules each (Tables 2 and 3). The nodules were located predominantly in the right upper lobe and left lower lobe. The mean preoperative largest nodule diameter on $\mathrm{CT}$ scan was $13.3 \mathrm{~mm}$, with a range of 4 to $44 \mathrm{~mm}$. The mean distance from the surface of the lung to the middle of the nodule was $22 \mathrm{~mm}$, with a range of 4 to $38 \mathrm{~mm}$. Thirty-one nodules were solid (57.4\%), whereas 23 were GGO $(42.6 \%)$.

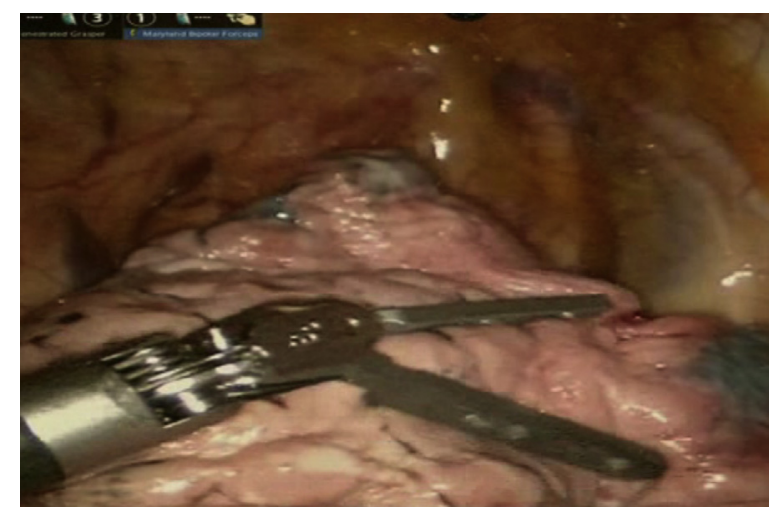

VIDEO 1. Intraoperative localization of posterior segmental right upper lobe small nodule by both methylene blue and near infrared autofluorescence. Video available at: http://www.jtcvsonline.org/article/ S0022-5223(17)30161-7/addons.
TABLE 1. Patient characteristics

\begin{tabular}{lc}
\hline \multicolumn{1}{c}{ Parameter } & n (\%) or mean \pm SD (range) \\
\hline Total number & 51 \\
Age, y & $62.6 \pm 8.6(41-86)$ \\
Sex & $26(51 \%)$ \\
$\quad$ Male & $25(49 \%)$ \\
$\quad$ Female & $29.6 \pm 7.3(15.9-50.1)$ \\
BMI & $31(60.8 \%)$ \\
Medical comorbidities & $45(88.2 \%)$ \\
$\quad$ COPD & $9(17.6 \%)$ \\
Current or former smoking & $7(13.7 \%)$ \\
Cancer & \\
Previous thoracic surgery & \\
Preoperative pulmonary function tests & $77.2 \% \pm 20.7(39 \%-113 \%)$ \\
$\quad$ FEV1 & $89.7 \% \pm 14.6(64 \%-136 \%)$ \\
FVC & $60.2 \% \pm 14.4(30 \%-88 \%)$ \\
$\quad$ DLCO &
\end{tabular}

$S D$, Standard deviation; $B M I$, body mass index; $C O P D$, chronic obstructive pulmonary disease; $F E V I$, forced expiratory volume in 1 second; $F V C$, forced vital capacity; $D L C O$, carbon monoxide diffusing capacity.

The mean largest diameter of solid nodules was $12.6 \mathrm{~mm}$ and comparable with that of GGOs $(13.9 \mathrm{~mm})$. In contrast, the distance from the pleural surface for solid nodules was greater than that for GGOs (24.1 mm vs $18.9 \mathrm{~mm}$ ), which suggests a tendency to consider ENBL more for solid nodules deeper than GGOs, for which the subsolid nature makes it difficult to visualize or palpate even superficial lesions (Table 3).

Postoperative data. All 54 nodules were resected successfully via a sublobar technique. Pathologic examination showed the mean weight of the resected specimen to be $31.9 \mathrm{~g}$ and the mean largest nodule diameter to be $13.9 \mathrm{~mm}$, with a range of 4 to $25 \mathrm{~mm}$. Final pathology revealed benign disease in $11(20.3 \%)$ and malignancy in $43(79.6 \%)$ of the 54 nodules. The most common benign diagnosis was granuloma $(5,9.3 \%)$. Malignancy included adenocarcinoma $(32,59.2 \%)$, squamous cell carcinoma (2, 3.7\%), metastatic disease $(7,13 \%)$, and neuroendocrine tumor $(2,3.7 \%)$. Three patients had 2 nodules each. One patient had a single adenocarcinoma plus a second granuloma, another had a neuroendocrine tumor plus a second inflammatory nodule, whereas the third had 2 separate adenocarcinomas.

\section{Operative Characteristics}

The mean total operative time was 212 minutes whereas the mean procedural time for the ENBL 29.1 minutes (Table 4). The dye used was MB only for the first 21 patients and a mixture of Isovue, $\mathrm{MB}$, and ICG in the remaining 30 patients. In addition, a fiducial also was placed at the site of the nodule in the first 2 procedures. The dye was clearly visible after all 54 localizations $(100 \%)$. 
TABLE 2. Nodule characteristics

\begin{tabular}{|c|c|}
\hline Parameter & n $(\%)$ or mean \pm SD $($ range $)$ \\
\hline Total number & 54 \\
\hline Patients with 1 nodule & $48(94.1 \%)$ \\
\hline Patients with 2 nodules & $3(5.9 \%)$ \\
\hline \multicolumn{2}{|l|}{ Preoperative data } \\
\hline \multicolumn{2}{|l|}{ Nodule location } \\
\hline Right upper lobe & $19(35.2 \%)$ \\
\hline Right middle lobe & $3(5.5 \%)$ \\
\hline Right lower lobe & $9(16.6 \%)$ \\
\hline Left upper lobe & $10(18.5 \%)$ \\
\hline Left lower lobe & $13(24.1 \%)$ \\
\hline \multicolumn{2}{|l|}{ CT nodule dimensions } \\
\hline Largest diameter, $\mathrm{mm}$ & $13.3 \pm 6(4-44)$ \\
\hline Depth from pleura, mm & $22 \pm 7.2(4-38)$ \\
\hline \multicolumn{2}{|l|}{ CT nodule characteristic } \\
\hline Ground-glass opacity & $23(42.6 \%)$ \\
\hline Solid nodule & $31(57.4 \%)$ \\
\hline \multicolumn{2}{|l|}{ Postoperative data } \\
\hline Weight of sublobar specimen, $\mathrm{g}$ & $31.9 \pm 26(5-133)$ \\
\hline Largest diameter of nodule, $\mathrm{mm}$ & $13.9 \pm 4.8(4-25)$ \\
\hline \multicolumn{2}{|l|}{ Tissue diagnosis } \\
\hline Malignancy & $43(79.6 \%)$ \\
\hline Adenocarcinoma & $32(59.2 \%)$ \\
\hline Squamous cell carcinoma & $2(3.7 \%)$ \\
\hline Neuroendocrine & $2(3.7 \%)$ \\
\hline Metastases (colorectal, renal cell) & $7(13 \%)$ \\
\hline Benign & $11(20.3 \%)$ \\
\hline Granuloma & $5(9.3 \%)$ \\
\hline Hamartoma & $2(3.7 \%)$ \\
\hline $\begin{array}{l}\text { Other benign (actinomycosis, } \\
\text { necrosis and inflammation, } \\
\text { organizing pneumonia, and fibrosis) }\end{array}$ & $4(7.4 \%)$ \\
\hline
\end{tabular}

Fifty-three of the 54 nodules were identified within the resected specimen $(98.1 \%)$. One nodule $(1.9 \%)$ was not found in the initial wedge-resection. Subsequently, the nodule was resected by robotic-assisted thoracoscopic surgery (RATS) right lower lobe posterior basilar segmentectomy adjacent to the initial staple line.

The procedure was completed with the use of minimally invasive thoracoscopic surgery in 49 patients $(96 \%)$, and initial sublobar resection of the nodule was accomplished in all 51 patients $(100 \%)$. Two patients underwent only VATS wedge resection, and in both cases, the nodules were readily visible and palpable, allowing a simple diagnostic wedge resection through a single incision

TABLE 3. Comparison of GGOs and solid nodules based on size and distance from pleural surface

\begin{tabular}{lcc}
\hline & GGOs & Solid nodules \\
\hline Largest diameter, mm & 13.9 & $12.6 \pm 5.7(5-25)$ \\
Distance from pleura, $\mathrm{mm}$ & 18.9 & $24.1 \pm 5.2(15-38)$ \\
\hline
\end{tabular}

GGO, Ground-glass opacity.
TABLE 4. Operative characteristics

\begin{tabular}{|c|c|}
\hline Parameter & $\begin{array}{c}\mathrm{N}(\%) \text { or } \\
\text { mean } \pm \mathrm{SD}(\text { range })\end{array}$ \\
\hline Total operative time, min & $212 \pm 52.8(140-290)$ \\
\hline ENBL time, min & $29.1 \pm 9(12-45)$ \\
\hline \multicolumn{2}{|l|}{ Marker used } \\
\hline $\mathrm{MB}+$ fiduciary & $2(3.9 \%)$ \\
\hline MB & $19(37.2 \%)$ \\
\hline $\mathrm{MB}+\mathrm{ICG}+$ Isovue & $30(58.8 \%)$ \\
\hline Dye was visible & $54(100 \%)$ \\
\hline \multicolumn{2}{|l|}{ Type of procedure } \\
\hline Thoracotomy & $2(3.9 \%)$ \\
\hline VATS & $2(3.9 \%)$ \\
\hline RATS & $47(92.2 \%)$ \\
\hline \multicolumn{2}{|l|}{ Type of initial resection } \\
\hline Wedge resection* & $38(73.1 \%)$ \\
\hline Segmentectomy & $14(26.9 \%)$ \\
\hline Lobectomy & $0(0 \%)$ \\
\hline Nodule was present in first resected specimen & $53(98.1 \%)$ \\
\hline Nodule was NOT present in first resected specimen & $1(1.9 \%)$ \\
\hline \multicolumn{2}{|l|}{ Type of final resection based on diagnosis } \\
\hline Wedge resection & $10(19.6 \%)$ \\
\hline Segmentectomy & $13(25.5 \%)$ \\
\hline Lobectomy & $28(54.9 \%)$ \\
\hline
\end{tabular}

without the need for robotic resection. Two patients required conversion to a thoracotomy secondary to dense adhesions but after pneumolysis the dye marking was clearly seen in both cases and corresponded to the location of the nodules. One of these patients had actinomycosis and the second patient had previous ipsilateral thoracotomy. The remaining 47 patients $(92.2 \%)$ underwent RATS for resection.

The type of initial sublobar resection of the nodule was either wedge resection $(38,73.1 \%)$ or anatomical segmentectomy $(14,26.9 \%)$. No initial lobectomies were

TABLE 5. Outcomes

\begin{tabular}{lc}
\hline \multicolumn{1}{c}{ Parameter } & N $(\%)$ or mean \pm SD (range) \\
\hline Length of stay, d & $3.9 \pm 2.3(2-16)$ \\
ICU stay, d & $0.06 \pm 0.4(0-3)$ \\
$90-d$ mortality & $0(0 \%)$ \\
Morbidity & \\
Acute renal failure & $2(3.9 \%)$ \\
Atrial fibrillation & $2(3.9 \%)$ \\
Reintubation & $1(2 \%)$ \\
Wound infection & $1(2 \%)$ \\
Ileus & $1(2 \%)$ \\
Chest tube reinsertion & $1(2 \%)$ \\
Need for home oxygen & $3(5.9 \%)$ \\
Discharge with Heimlich valve & $3(5.9 \%)$ \\
\hline$S D$, Standard deviation; $I C U$, intensive care unit.
\end{tabular}

$S D$, Standard deviation; $I C U$, intensive care unit. 
TABLE 6. ENBL in literature

\begin{tabular}{lclc}
\hline \multicolumn{1}{c}{ Study } & Number of patients & Timing of ENBL & Dccuracy \\
\hline Bolton et al, 2014 22 & 14 & Intraoperative & $100 \%$ \\
Krimsky et al, 2014 & 21 & Combination (5 centers) & MB \\
Tay et al, 2015 & 6 & Preoperative & MB or indigo carmine \\
2016 study & 51 & Intraoperative & $100 \%$ \\
\hline
\end{tabular}

$E N B L$, Electromagnetic navigational bronchoscopic localization; $M B$, methylene blue dye; $I C G$, indocyanine green; $I V$, Isovue.

performed. The final definitive resection based on frozen section examination was lobectomy $(28,54.9 \%)$, anatomical segmentectomy $(13,25.5 \%)$, and wedge resection $(10,19.6 \%)$.

\section{Clinical Outcomes}

There were no mortalities at 90 days (Table 5). The mean hospital length of stay was 3.9 days (2-16). Postoperative complications were noted in 6 patients $(11.8 \%)$ and included atrial fibrillation $(2,3.9 \%)$, acute renal failure $(2,3.9 \%)$, reintubation for hypoventilation $(1,2 \%)$, and recurrent pneumothorax requiring chest tube reinsertion $(1,2 \%)$.

\section{DISCUSSION}

Despite the well-recognized advantages of thoracoscopic minimally invasive surgery, there is likewise an undisputed fact that small, deep, or subsolid pulmonary nodules can be difficult to localize by these techniques. In fact, they can be difficult to find even with thoracotomy. When such nodules cannot be located accurately, the surgeon must spend more time searching for the nodule and may be inclined to proceed with a larger resection. ${ }^{31,32}$ Frequently, the surgeon will even convert to thoracotomy to attempt bimanual palpation. $^{33}$

Indications for preoperative localization of pulmonary nodules have been suggested depending on various factors, including size, depth from surface, and density of nodule. In one study, if the distance of the nodule from the pleural surface was greater than $5 \mathrm{~mm}$ or if the nodule was less than $10 \mathrm{~mm}$ in size, there was a $63 \%$ probability of failure to detect the nodule. ${ }^{33}$ Nakashima and colleagues ${ }^{34}$ developed 3 criteria for preoperative localization: (1) nodule diameter of $5 \mathrm{~mm}$ or less; (2) ratio of maximum diameter of nodule to minimum distance between pleural surface and inferior border of nodule of 0.5 or less; and (3) nodule is of low density on CT. They argued that preoperative localization should be considered if at least 2 of these criteria were met. ${ }^{34}$ It is our opinion that the experience of the surgeon in evaluating the CT scan is equally important in deciding when a nodule may be difficult to localize.

Attempts at preoperative localization of lung nodules are not new. ${ }^{5-20}$ In 1994, Lenglinger and colleagues ${ }^{5}$ described CT-guided percutaneous staining of pulmonary nodules with MB. Since then, numerous other techniques have been described and perhaps the most popular is
CT-guided hook wire placement. Ichinose and colleagues ${ }^{7}$ described this technique in 417 patients with 500 lesions. Localization was nearly universal but was associated with a complication rate of $15.1 \%$ that included pneumothorax requiring chest tube placement $(4.6 \%)$, hemoptysis, and pulmonary hematoma $(10.3 \%)$. Although the authors described a very low incidence of wire dislodgment $(0.4 \%)$, this is not always the case. Dislodgement of the wire can occur due to an iatrogenic pneumothorax by the wire or at the time of surgery after initiation of thoracoscopy or while manipulating the lung. ${ }^{10,11,14}$

Intraoperative ultrasound-guided localization of pulmonary nodules also has been described ${ }^{26,27}$; however, this technique is difficult to master and requires the lung to be completely deflated, which often is difficult to achieve in the presence of chronic obstructive pulmonary disease and adhesions.

CT-guided percutaneous placement of fiducials for localization also has been used; however, if placed, the fiducial should be found and resected with the specimen. Complications of fiducial dislodgement, embolization, migration, and parenchymal hematoma have been described.

All these techniques with the exception of intraoperative ultrasound usually require being placed preoperatively in a different location than the operating room and by a different physician than the surgeon. Frequently, these procedures also are performed a day or more before the operation, and thus when a complication does occur, such as a pneumothorax or hemothorax, there is a potential for delay in both the evaluation and management of the patient. In addition to the safety concerns, there are issues of overall cost of requiring 2 procedure rooms with 2 clinical teams on top of the discomfort and inconvenience for the patient.

ENBL for resection of IPNs has been described previously in a few studies. ${ }^{22,23,25}$ Krimsky and colleagues ${ }^{23}$ described a multi-institutional study of 21 patients who underwent preoperative or intraoperative ENBL using MB or indigo carmine dye for surgical resection by VATS or RATS in 5 centers. The visceral pleural marker was visible in 17 patients $(81 \%)$ and not identified in $4(19 \%)$. Bolton and colleagues $^{22}$ described a study of 14 patients who underwent intraoperative ENBL using MB for surgical resection by RATS. The median time for the ENBL portion of the procedure was 28 minutes, and no patients underwent conversion to an open procedure. Tay and colleagues ${ }^{25}$ 
described a study of 6 patients who underwent preoperative ENBL using MB for surgical resection by VATS. Pleural staining by dye was visible thoracoscopically in all 6 lesions, which were all fully excised by wedge resection. Table 6 outlines the characteristics of these reports and compares them to this one.

Direct injection of ICG into tissues has been used for NIR fluorescence image-guided surgery has been performed by in patients with gastric, ${ }^{35-37}$ breast, ${ }^{38-41}$ and $\operatorname{skin}^{42,43}$ cancers. This has been used mainly for sentinel node detection and the same concept has been applied to lung cancer surgery by thoracoscopic injection of ICG around the tumor. ${ }^{30,44-49}$ It also has been injected into lung tumors for photothermal ablation. ${ }^{50}$ Its use for localization by ENBL guidance has only been described in a porcine animal model. ${ }^{51}$

Our study is the largest to date to describe the technique of ENBL in 51 patients with 54 IPNs for sublobar resection. It is also the only one to describe the use of NIR fluorescence for this technique. It describes our evolution in marker use and shows that our current combination of MB, ICG, and Isovue is ideal for this procedure and easily reproducible. It also describes how ENBL can be performed intraoperatively by the thoracic surgical team. It is important to stress that ENBL was only performed for those nodules deemed to be potentially difficult to localize by minimally invasive surgical techniques based on size, depth, or density.

In our study, the dye was clearly visible in all 54 nodules $(100 \%)$. The localization success rate of the technique was $98.1 \%$, with a false-positive rate of $1.9 \%$. No adverse events were related to the placement of the dye marker. Sublobar resection of the nodule was accomplished in all 51 patients $(100 \%)$, and $96 \%$ of the procedures were completed in a minimally invasive fashion (RATS or VATS). We believe this accounts for our low morbidity and short hospital stay.

ENBL does add extra costs, and further studies will be needed to investigate its cost effectiveness. The cost, however, may be offset when other factors, such as operating room time and shorter hospital stay, are taken into account. Our study is not without limitations. It is a retrospective, nonrandomized study, which creates possible selection and chronological biases. We believe this was circumvented in part by having a multidisciplinary decision for performing ENBL on each patient in the study. Although $21.5 \%$ of our patients had benign diagnoses, the risk of malignancy was felt to be sufficiently high in these patients to warrant surgical resection. This incidence is in the range reported by other studies of $9 \%$ to $40 \%{ }^{52-54}$

\section{CONCLUSIONS}

ENBL is a safe and accurate intraoperative modality for targeted sublobar resection of IPNs that are deemed difficult to localize. Prospective randomized studies are needed to further substantiate these findings. This technique may help avoid the need for conversion to open surgery or for requiring larger resections. It also may help compensate for the lack of tactile haptic feedback associated with minimally invasive surgery.

\section{Webcast}

You can watch a Webcast of this AATS meeting presentation by going to: http://webcast.aats.org/2016/Video/ Tuesday/05-17-16_Room_337_0800_Abbas-800.mp4.

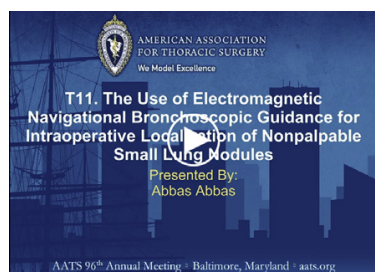

\section{Conflict of Interest Statement}

Abbas E. Abbas, MD, is a paid consultant for Boston Scientific, Inc, and Intuitive Surgical, Inc. Neither entity was involved in the preparation of this manuscript. All other authors have nothing to disclose with regard to commercial support

\section{References}

1. The National Lung Screening Trial Research Team. Reduced lung-cancer mortality with low-dose computed tomographic screening. $N$ Engl J Med. 2011;365:395-409.

2. Naidich DP, Bankier AA, MacMahon H, Schaefer-Prokop CM, Pistolesi M, Goo JM, et al. Recommendations for the management of subsolid pulmonary nodules detected at CT: a statement from the Fleischner Society. Radiology. 2013;266:304-17.

3. Krochmal R, Arias S, Yarmus L, Feller-Kopman D, Lee H. Diagnosis and management of pulmonary nodules. Expert Rev Respir Med. 2014;8:677-91.

4. Raad RA, Suh J, Harari S, Naidich DP, Shiau M, Ko JP. Nodule characterization: subsolid nodules. Radiol Clin North Am. 2014;52:47-67.

5. Lenglinger FX, Schwarz CD, Artmann W. Localization of pulmonary nodules before thoracoscopic surgery: value of percutaneous staining with methylene blue. AJR Am J Roentgenol. 1994;163:297-300.

6. Moon SW, Wang YP, Jo KH, Kwack MS, Kim SW, Kwon OK, et al. Fluoroscopy-aided thoracoscopic resection of pulmonary nodule localized with contrast media. Ann Thorac Surg. 1999;68:1815-20.

7. Ichinose J, Kohno T, Fujimori S, Harano T, Suzuki S. Efficacy and complications of computed tomography-guided hook wire localization. Ann Thorac Surg. 2013; 96:1203-8.

8. Sancheti MS, Lee R, Ahmed SU, Pickens A, Fernandez FG, Small WC, et al. Percutaneous fiducial localization for thoracoscopic wedge resection of small pulmonary nodules. Ann Thorac Surg. 2014;97:1914-8; discussion 1919.

9. Daniel TM. A proposed diagnostic approach to the patient with the subcentimeter pulmonary nodule: techniques that facilitate video-assisted thoracic surgery excision. Semin Thorac Cardiovasc Surg. 2005;17:115-22.

10. Ciriaco P, Negri G, Puglisi A, Nicoletti R, Del Maschio A, Zannini P. Video-assisted thoracoscopic surgery for pulmonary nodules: rationale for preoperative computed tomography-guided hookwire localization. Eur J Cardiothorac Surg. 2004;25:429-33.

11. Chen S, Zhou J, Zhang J, Hu H, Luo X, Zhang Y, et al. Video-assisted thoracoscopic solitary pulmonary nodule resection after CT-guided hookwire localization: 43 cases report and literature review. Surg Endosc. 2011;25:1723-9.

12. McConnell PI, Feola GP, Meyers RL. Methylene blue-stained autologous blood for needle localization and thoracoscopic resection of deep pulmonary nodules. J Pediatr Surg. 2002;37:1729-31. 
13. Lizza N, Eucher P, Haxhe JP, De Wispelaere JF, Johnson PM, Delaunois L. Thoracoscopic resection of pulmonary nodules after computed tomographicguided coil labeling. Ann Thorac Surg. 2001;71:986-8.

14. Seo JM, Lee HY, Kim HK, Choi YS, Kim J, Shim YM, et al. Factors determining successful computed tomography-guided localization of lung nodules. J Thorac Cardiovasc Surg. 2012;143:809-14.

15. Nomori H, Horio H, Naruke T, Suemasu K. Fluoroscopy-assisted thoracoscopic resection of lung nodules marked with lipiodol. Ann Thorac Surg. 2002;74:170-3.

16. Ambrogi MC, Dini P, Boni G, Melfi F, Lucchi M, Fanucchi O, et al. A strategy for thoracoscopic resection of small pulmonary nodules. Surg Endosc. 2005;19:1644-7.

17. Ambrogi MC, Melfi F, Zirafa C, Lucchi M, De Liperi A, Mariani G, et al. Radio-guided thoracoscopic surgery (RGTS) of small pulmonary nodules. Surg Endosc. 2012;26:914-9.

18. Watanabe K, Nomori H, Ohtsuka T, Kaji M, Naruke T, Suemasu K. Usefulness and complications of computed tomography-guided lipiodol marking for fluoroscopy-assisted thoracoscopic resection of small pulmonary nodules: experience with 174 nodules. J Thorac Cardiovasc Surg. 2006;132:320-4.

19. Doo KW, Yong HS, Kim HK, Kim S, Kang EY, Choi YH. Needlescopic resection of small and superficial pulmonary nodule after computed tomographic fluoroscopy-guided dual localization with radiotracer and hookwire. Ann Surg Oncol. 2015;22:331-7.

20. Kang DY, Kim HK, Kim YK, Yong HS, Kang EY, Choi YH. Needlescopy-assisted resection of pulmonary nodule after dual localisation. Eur Respir J. 2011;37:13-7.

21. Endo M, Kotani Y, Satouchi M, Takada Y, Sakamoto T, Tsubota N, et al. CT fluoroscopy-guided bronchoscopic dye marking for resection of small peripheral pulmonary nodules. Chest. 2004;125:1747-52.

22. Bolton WD, Howe H III, Stephenson JE. The utility of electromagnetic navigational bronchoscopy as a localization tool for robotic resection of small pulmonary nodules. Ann Thorac Surg. 2014;98:471-5; discussion 475-6.

23. Krimsky WS, Minnich DJ, Cattaneo SM, Sarkar SA, Harley DP, Finley DJ, et al. Thoracoscopic detection of occult indeterminate pulmonary nodules using bronchoscopic pleural dye marking. J Community Hosp Intern Med Perspect. 2014;4:10.3402/jchimp.v4.23084.

24. Anayama T, Qiu J, Chan H, Nakajima T, Weersink R, Daly M, et al. Localization of pulmonary nodules using navigation bronchoscope and a near-infrared fluorescence thoracoscope. Ann Thorac Surg. 2015;99:224-30.

25. Tay JH, Wallbridge PD, Larobina M, Russell PA, Irving LB, Steinfort DP. Electromagnetic navigation bronchoscopy-directed pleural tattoo to aid surgical resection of peripheral pulmonary lesions. J Bronchology Interv Pulmonol. 2016;23:245-50.

26. Kondo R, Yoshida K, Hamanaka K, Hashizume M, Ushiyama T, Hyogotani A, et al. Intraoperative ultrasonographic localization of pulmonary ground-glass opacities. J Thorac Cardiovasc Surg. 2009;138:837-42.

27. Santambrogio R, Costa M, Strada D, Barabino M, Conti M, Bertolini E, et al. Intraoperative ultrasound patterns predict recurrences after surgical treatments for hepatocellular carcinoma. J Ultrasound. 2010;13:150-7.

28. Makris D, Scherpereel A, Leroy S, Bouchindhomme B, Faivre JB, Remy J, et al. Electromagnetic navigation diagnostic bronchoscopy for small peripheral lung lesions. Eur Respir J. 2007;29:1187-92.

29. Vandoni RE, Cuttat JF, Wicky S, Suter M. CT-guided methylene-blue labelling before thoracoscopic resection of pulmonary nodules. Eur J Cardiothorac Surg. 1998; 14:265-70

30. Yamashita S, Tokuishi K, Anami K, Miyawaki M, Moroga T, Kamei M, et al. Video-assisted thoracoscopic indocyanine green fluorescence imaging system shows sentinel lymph nodes in non-small-cell lung cancer. J Thorac Cardiovasc Surg. 2011;141:141-4

31. Saito H, Minamiya Y, Matsuzaki I, Tozawa K, Taguchi K, Nakagawa T, et al. Indication for preoperative localization of small peripheral pulmonary nodules in thoracoscopic surgery. J Thorac Cardiovasc Surg. 2002;124:1198-202.

32. Powell TI, Jangra D, Clifton JC, Lara-Guerra H, Church N, English J, et al. Peripheral lung nodules: fluoroscopically guided video-assisted thoracoscopic resection after computed tomography-guided localization using platinum microcoils. Ann Surg. 2004;240:481-8; discussion 488-9.

33. Suzuki K, Shimohira M, Hashizume T, Ozawa Y, Sobue R, Mimura M, et al. Usefulness of CT-guided hookwire marking before video-assisted thoracoscopic surgery for small pulmonary lesions. J Med Imaging Radiat Oncol. 2014;58:657-62.

34. Nakashima S, Watanabe A, Obama T, Yamada G, Takahashi H, Higami T. Need for preoperative computed tomography-guided localization in video-assisted thoracoscopic surgery pulmonary resections of metastatic pulmonary nodules. Ann Thorac Surg. 2010;89:212-8.

35. Takahashi N, Nimura H, Fujita T, Yamashita S, Mitsumori N, Yanaga K. Quantitative assessment of visual estimation of the infrared indocyanine green imaging of lymph nodes retrieved at sentinel node navigation surgery for gastric cancer. BMC Surg. 2016;16:35.

36. Mitsumori N, Nimura H, Takahashi N, Kawamura M, Aoki H, Shida A, et al. Sentinel lymph node navigation surgery for early stage gastric cancer. World $J$ Gastroenterol. 2014;20:5685-93.

37. Miyashiro I, Hiratsuka M, Kishi K, Takachi K, Yano M, Takenaka A, et al. Intraoperative diagnosis using sentinel node biopsy with indocyanine green dye in gastric cancer surgery: an institutional trial by experienced surgeons. Ann Surg Oncol. 2013;20:542-6.

38. Samorani D, Fogacci T, Panzini I, Frisoni G, Accardi FG, Ricci M, et al. The use of indocyanine green to detect sentinel nodes in breast cancer: a prospective study. Eur J Surg Oncol. 2015;41:64-70.

39. Xiong L, Gazyakan E, Yang W, Engel H, Hunerbein M, Kneser U, et al Indocyanine green fluorescence-guided sentinel node biopsy: a meta-analysis on detection rate and diagnostic performance. Eur J Surg Oncol. 2014;40:843-9.

40. Ballardini B, Santoro L, Sangalli C, Gentilini O, Renne G, Lissidini G, et al. The indocyanine green method is equivalent to the (9)(9)mTc-labeled radiotracer method for identifying the sentinel node in breast cancer: a concordance and validation study. Eur J Surg Oncol. 2013;39:1332-6.

41. Abe H, Mori T, Umeda T, Tanaka M, Kawai Y, Shimizu T, et al. Indocyanine green fluorescence imaging system for sentinel lymph node biopsies in early breast cancer patients. Surg Today. 2011;41:197-202.

42. Fujisawa Y, Nakamura Y, Kawachi Y, Otsuka F. A custom-made, low-cost intraoperative fluorescence navigation system with indocyanine green for sentinel lymph node biopsy in skin cancer. Dermatology. 2011;222:261-8.

43. Tsujino Y, Mizumoto K, Matsuzaka Y, Niihara H, Morita E. Fluorescence navigation with indocyanine green for detecting sentinel nodes in extramammary Paget's disease and squamous cell carcinoma. J Dermatol. 2009:36:90-4.

44. Yamashita S, Tokuishi K, Miyawaki M, Anami K, Moroga T, Takeno S, et al Sentinel node navigation surgery by thoracoscopic fluorescence imaging system and molecular examination in non-small cell lung cancer. Ann Surg Oncol. 2012 19:728-33.

45. Moroga T, Yamashita S, Tokuishi K, Miyawaki M, Anami K, Yamamoto S, et al. Thoracoscopic segmentectomy with intraoperative evaluation of sentinel nodes for stage I non-small cell lung cancer. Ann Thorac Cardiovasc Surg. 2012;18:89-94.

46. Nomori H, Cong Y, Sugimura H. Utility and pitfalls of sentinel node identification using indocyanine green during segmentectomy for cT1NOMO non-small cell lung cancer. Surg Today. 2016;46:908-13.

47. Akopov AL, Papayan GV, Chistyakov IV, Karlson A, Gerasin AV, Agishev AS Intraoperative detection of sentinel lymph nodes using infrared imaging system in local non-small cell carcinoma of lung. Vestn Khir Im I I Grek. 2015;174:13-7.

48. Gilmore DM, Khullar OV, Jaklitsch MT, Chirieac LR, Frangioni JV, Colson YL. Identification of metastatic nodal disease in a phase 1 dose-escalation trial of intraoperative sentinel lymph node mapping in non-small cell lung cancer using near-infrared imaging. J Thorac Cardiovasc Surg. 2013;146:562-70; discussion 569-70.

49. Ito N, Fukuta M, Tokushima T, Nakai K, Ohgi S. Sentinel node navigation surgery using indocyanine green in patients with lung cancer. Surg Today 2004;34:581-5.

50. Hirohashi K, Anayama T, Wada H, Nakajima T, Kato T, Keshavjee S, et al. Photothermal ablation of human lung cancer by low-power near-infrared laser and topical injection of indocyanine green. J Bronchology Interv Pulmonol. 2015;22:99-106

51. Wada H, Hirohashi K, Anayama T, Nakajima T, Kato T, Chan HH, et al. Minimally invasive electro-magnetic navigational bronchoscopy-integrated near-infrared-guided sentinel lymph node mapping in the porcine lung. PLoS One. 2015;10:e126945.

52. Heo EY, Lee KW, Jheon S, Lee JH, Lee CT, Yoon HI. Surgical resection of highly suspicious pulmonary nodules without a tissue diagnosis. Jpn J Clin Oncol. 2011 41:1017-22.

53. Smith MA, Battafarano RJ, Meyers BF, Zoole JB, Cooper JD, Patterson GA Prevalence of benign disease in patients undergoing resection for suspected lung cancer. Ann Thorac Surg. 2006;81:1824-8; discussion 1828-9.

54. Carillo GA, Vazquez JE, Villar AF. Prevalence of benign pulmonary lesions excised for suspicion of malignancy: could it reflect a quality management index of indeterminate lung lesions? Korean J Thorac Cardiovasc Surg. 2014;47: 458-64.

Key Words: nodule, localization, electromagnetic navigation, robotic, sublobar, resection, lung cancer 


\section{Discussion}

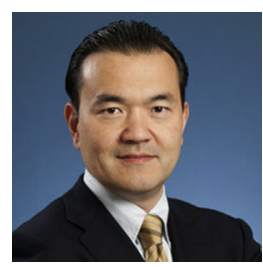

Dr K. Yasufuku (Toronto, Ontario, Canada). Thank you very much for the excellent presentation.

I have one comment about indocyanine green (ICG). I think you did not mention it in your presentation, interstitial injection of ICG is an off-label indication. My first question is whether you had institutional review board approval for use.

For my second question, I think there is a limit in terms of the reach for electromagnetic navigational bronchoscopic localization. If a nodule is not close to a bronchus or a subsubsegmental bronchus, perhaps you may not be able to inject your methylene blue or your dye. Were there some selection criteria when you were doing these cases? Were you able to use the electromagnetic navigational bronchoscopy for any kind of nonpalpable small nodules, or were you selecting patients and perhaps you were doing other techniques for localization?

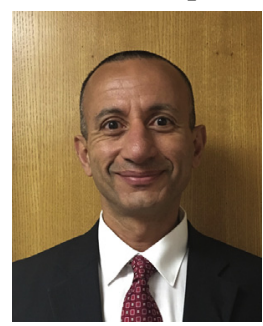

Dr Abbas E. Abbas. Thank you for your questions. ICG has been used for tissue injection in multiple tumors, including esophageal and gastric tumors, in my institution. I am not aware of its off-label usage, but I will look into it. Thank you for bringing that up.

The other question was whether we had an airway that facilitated navigating to these nodules, and actually, the way I do navigational bronchoscopy is to navigate to the closest central airway, and then the rest of the navigation, especially since you are going to be resecting that part of the lung, can actually be done transparenchymally. I do not really rely on having a bronchus very close to the nodule. So this technique was done for all comers.

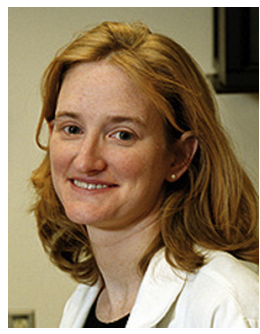

Dr Y. Colson (Boston, Mass). Thank you again. It was a very nice presentation. We have probably done about 50 to 70 patients. It is off-label and you do need an IRB in general until we get really standard of care, which we are not there yet.

I have 2 questions. You added ICG to the methylene blue and it is not quite clear to me why you did that since the Isovue is really what you want-to be able to see it thoracoscopically. What is the advantage of adding both of them? They look exactly the same when we have done it.

Dr Abbas. Thank you for your question. Actually, what we found is that methylene blue seems to diffuse at a faster pace whereas ICG seems to remain localized at the site of the injection. I didn't really show that on my slides. When we compared the size of the methylene blue dispersion compared with the ICG, the methylene blue had clearly a much wider diffusion on the surface.

Dr Colson. The second part of that question, then, is have you looked at lymph nodes?

Dr Abbas. We did perform a nodal dissection in all the malignant cases.

Dr Colson. And you did not see any color change?

Dr Abbas. No. We didn't see any evidence of sentinel nodes.

Dr Colson. So the trick is probably the particle size, just like Joe Friedberg talked about. If you look at the particle size of methylene blue versus the particle size of ICG, the ICG is bigger. That is why it migrates slower. We have linked it to albumin because it slows it down further to get to the nodes, and that may be why when we have looked at methylene blue, we never get sentinel nodes. It's just data to incorporate as to why there is probably a difference between the two.

Dr Abbas. It's an excellent point, and I agree with you that the next step should be to carry it further to see its dispersion to the local nodes.

Dr Colson. Thank you.

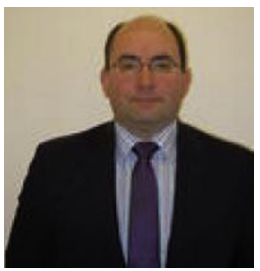

Dr D. Waller (Leicester, United Kingdom). We have no experience with this. My pathologists would probably be worried trying to interpret a frozen with dye injected. Does it have any effect on the accuracy of the frozen section?

Dr Abbas. It didn't seem to-

Dr Waller. You resected some benign lesions. Were any of those false-positive or false-negative?

Dr Abbas. We had one false-positive localization where the lesion was not located in the wedge resection. We subsequently found it in an adjacent segmentectomy

Dr Waller. But all the frozen sections were accurate?

Dr Abbas. They were accurate, yes.

Dr Waller. The injection of the dye doesn't affect the pathologist's interpretation? This is so that I can reassure them.

Dr Abbas. It did not in our series. 